\title{
Research in the Field of Health, Dentistry, Telehealth and Teledentistry
}

\section{Ana Estela HADDAD(a) Marcelo BÖNECKER ${ }^{(b)}$ Mary Caroline SKELTON-MACEDO ${ }^{(c)}$}

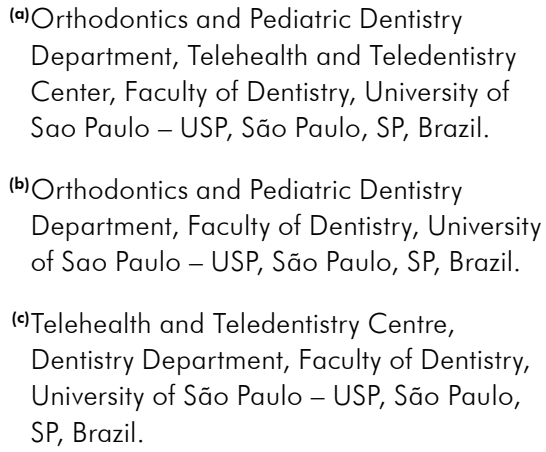

http://dx.doi.org/10.1590/1807-3107BOR-2014.vol28.0001
G lobal trends in Higher Education points, as guidelines to be pursued, lifelong learning, public accountability and the social dimension of higher education and research.

The information and communication technologies (ICT) add a new dimension, influenced by the perception that the current society is globally interconnected, that our knowledge and our vision of the world is transitory, is always incomplete and reprocessing, that we can access continuously and permanently any and all information, and create simulations of the real world .

Reflecting the perspective of the information society we can ask what changed after the publication of the Diretrizes Curriculares Nacionais para a Odontologia (DCN - Brazilian guidelines for undegraduate courses of dentistry and other health professions) in Brazil. Government programs such as Pro-Saúde and PETSaúde, from the Brazilian Ministry of Health in partnership with the Brazilian Ministry of Education, has supported and strengthened the implementation of DCN in the 14 Health Professions.

These programs, implemented since 2006, have benefited almost 100,000 undergraduate students in the Health field, approximately 1,000 undergraduate courses and involved health care professionals in more than 1,000 Sistema Único de Saúde (SUS - Brazilian Unified Health System) health services, seeking reorientation training for health professionals, and including the expansion in the use of ICT to strengthen applied research to teaching, guided by clinical and social relevance. Such an approach has added value to practice, producing real experience of the daily work.

The use of ICT applied to health, whether in education (distance learning), research, or in health care (telecare), relates to the emergence of Telehealth, Telemedicine, Teledentistry, and puts new elements also for choosing and planning research. To Sigulem (1997) digital health practice refers to the set of techniques, practices, attitudes, and ways of thinking and new values that develop as a result of the growth of the digital space.

In the case of telecare, Brazil has a success case with the implementation of the Telessaúde Brasil (www.telessaudebrasil.org.br - Brazilian Telehealth Program), whose results show impacts on the solvability of care, lower costs and continuing education of health professionals. With this program, in addition to establishing protocols for teleconsultation, new concepts and formats aggregation of scientific knowledge and research for easy use by health professionals in service have been developed, such as the Formative Second Opinion.

The production of knowledge and the development of research in this area resulted in the creation of a new scientific journal, the Brazilian Journal of Telehealth (www.jbtelessaude.com.br), in which the latest edition highlights the Brazilian experiences in Teledentistry. 
The University of São Paulo's Faculty of Dentistry (FOUSP) created in 2006, around the same time of the development of the foundations of Brazilian Telehealth, its teledentistry center, to support the use of ICT applied to education and research. Among its initiatives are creating the teledentistry discipline at undergraduate and postgraduate courses, their inclusion in one of the research lines of the Programa de Pós-Graduação em Ciências Odontológicas (post-graduate dental science program), the use of Moodle as interactive educational resource by more than 30 disciplines at undergraduate and postgraduate courses. It also established the Brazilian teledentistry network, in partnership with the Associação Brasileira de Ensino Odontológico (Abeno) and the Latin American and Caribbean Center on Health Sciences (Bireme/ PAHO). And they are now preparing to offer a distance learning course to support the implementation of new teledentistry centers in dental schools throughout Brazil, interested in advancing the use of ICT .

The center for telehealth and teledentistry is defined as the space constituted by higher education institutions, with installed capacity, in terms of infrastructure, technical and pedagogical multidisciplinary team, having as main objectives:

- support professors and students in developing skills and abilities for the use of information and communication technologies (ICT) applied to teaching, content production (learning objects) research and health care;

- support the teaching-service integration and teamwork in multidisciplinary health through the provision of training and preparation at teleconsultation, elaboration and cataloging of the Formative Second Opinions.

It is worth noting the experience of the Departamento de Odontologia Pediátrica of FOUSP (department of pediatric dentistry - FOUSP) that since 2007, began to minister the telepediatric dentistry discipline, interactive educational activities in Moodle, having the post graduate students as tutors. In addition to expanding the opportunities for learning and interaction among undergraduate students, postgraduate students and faculty, it has opened new areas of research applied to the teaching-learning process and added to the graduate students, one more skill, mentoring as relevant for teacher education today.

Looking further to these movements, we can see that the European Union created the OpenAIRE, a network of open access repositories, integrating information systems, scientific articles and agencies, in order to optimize the circulation, access to and transfer of scientific knowledge .

In Brazil, the Universidade Aberta do SUS (Unasus Brazilian National Health System university) developed the first open access repository in educational health (https://ares.unasus.gov.br/acervo), aiming to preserve and publish educational resources focused on educational content. It is a public collection with educational resources in various formats, produced collaboratively.

The Council of Rectors of State of Sao Paulo Universities launched last month, during the $4^{\text {th }}$ Luso-Brazilian Conference on Open Access (Confoa), its repository of scientific production, whereby any scientific work from Universidade de São Paulo, Universidade Estadual de Campinas and Universidade Estadual Paulista will be available soon, in open access at the same portal.

On that occasion it was mentioned, in relation to the European experience, the real value of the repository is in its potential to interconnect in a network of repositories, which can provide open and unified access to research results. Each repository is individually valuable to their respective institution, but it has very limited value in isolation, for research and science. Also notable is that the glue technique that enables this integration is interoperability, that is the ability to communicate, interact and work together, between the different systems, transferring data, metadata and digital objects in a reusable format.

Understanding these trends leads us to seek for expanding our collaborative work, and getting ourselves appropriated of the potential of ICT to achieve new dimensions in the production and dissemination of scientific knowledge and its collaborative organizational network structure. 